\title{
Review \\ Delafloxacin, Finafloxacin, and Zabofloxacin: Novel Fluoroquinolones in the Antibiotic Pipeline
}

\author{
Béla Kocsis * D, Dániel Gulyás and Dóra Szabó \\ Institute of Medical Microbiology, Semmelweis University, 1089 Budapest, Hungary; \\ gulyas.daniel@med.semmelweis-univ.hu (D.G.); szabo.dora@med.semmelweis-univ.hu (D.S.) \\ * Correspondence: kocsis.bela@med.semmelweis-univ.hu
}

Citation: Kocsis, B.; Gulyás, D.; Szabó, D. Delafloxacin, Finafloxacin, and Zabofloxacin: Novel

Fluoroquinolones in the Antibiotic Pipeline. Antibiotics 2021, 10, 1506. https://doi.org/10.3390/ antibiotics 10121506

Academic Editors: Carlos M. Franco and Marc Maresca

Received: 18 October 2021

Accepted: 6 December 2021

Published: 8 December 2021

Publisher's Note: MDPI stays neutral with regard to jurisdictional claims in published maps and institutional affiliations.

Copyright: (c) 2021 by the authors. Licensee MDPI, Basel, Switzerland. This article is an open access article distributed under the terms and conditions of the Creative Commons Attribution (CC BY) license (https:// creativecommons.org/licenses/by/ $4.0 /)$.

\begin{abstract}
Novel antimicrobial agents, approved for clinical use in past years, represent potential treatment options for various infections. In this review, we summarize the most important medical and microbiological features of three recently approved fluoroquinolones, namely delafloxacin, finafloxacin, and zabofloxacin. Delafloxacin possesses an anionic chemical structure, and represents broad-spectrum activity, as it targets both bacterial DNA gyrase and topoisomerase IV enzymes of gram-positive and gram-negative bacteria with equal affinity. Its molecular surface is larger than that of other fluoroquinolones, and it has enhanced antibacterial efficacy in acidic environments. Delafloxacin has been approved to treat acute bacterial skin and skin-structure infections, as well as community-acquired bacterial pneumonia. Finafloxacin has a zwitterionic chemical structure, and targets both DNA gyrase and topoisomerase IV enzymes. This enables a broad antibacterial spectrum; however, finafloxacin has so far only been approved in ear-drops to treat bacterial otitis externa. Zabofloxacin is also a broad-spectrum fluoroquinolone agent, and was first approved in South Korea to treat acute bacterial exacerbation of chronic obstructive pulmonary disease. The introduction of these novel fluoroquinolones into daily practice extends the possible indications of antibiotics into different bacterial infections, and provides treatment options in difficult-to-treat infections. However, some reports of delafloxacin resistance have already appeared, thus underlining the importance of the prudent use of antibiotics.
\end{abstract}

Keywords: novel antibiotics; multidrug resistance; fluoroquinolones

\section{Introduction}

Nowadays, the emergence and dissemination of multiresistant pathogens poses an ongoing challenge [1-3]. Increasing numbers of infections caused by antibiotic-resistant bacteria are being diagnosed worldwide, and the most well-known group of multiresistant pathogens is the ESKAPE group, namely Enterococcus faecium, Staphylococcus aureus, Klebsiella pneumoniae, Acinetobacter baumannii, Pseudomonas aeruginosa, and Enterobacter spp. [4]. These pathogens frequently develop resistance to various antibiotics, and are common causative agents of difficult-to-treat nosocomial infections, including bloodstream, wound, skin, and urinary tract infections (UTIs), as well as ventilator-associated pneumonia (VAP) [5]. Due to the limited number of effective antibiotics, infections caused by ESKAPE pathogens are associated with significantly high morbidity and mortality rates [6-8].

The need for novel potent antimicrobial agents is seen worldwide. The World Health Organization (WHO) released a priority list detailing the discovery and development of novel antibiotics [9]. On this WHO priority list, ESKAPE pathogens are listed among "critical" and "high" priority groups; therefore, development of antibiotics is urgently needed against these pathogens [9].

During the past years, huge efforts have been made towards the development of novel agents; several antimicrobial agents have been synthetized, and some of them are already approved for clinical use [10]. The Food and Drug Administration (FDA) approved 
plazomicin as a new aminoglycoside, which has been recommended for therapy of complicated urinary tract infections caused by multidrug-resistant Enterobacteriaceae [11]. Cefiderocol, a siderophore cephalosporin, has been approved for therapy of infections caused by carbapenem-resistant gram-negative bacteria [12]. Different combinations of beta-lactams and beta-lactamase-inhibitors have also been approved for clinical use, namely meropenem/vaborbactam, imipenem/cilastatin/relebactam, ceftazidime/avibactam, and ceftolozane/tazobactam $[10,13,14]$. New fluoroquinolones with enhanced antibacterial features are also under development, and some of them are marketed $[15,16]$. In this review we summarize the most important medical and microbiological features of three recently approved fluoroquinolones, namely delafloxacin, finafloxacin and zabofloxacin.

\section{Fluoroquinolones}

Fluoroquinolones are nucleic acid synthesis inhibitors, and their main targets are bacterial gyrase and topoisomerase IV enzymes. Fluoroquinolones were first synthetized in the 1970s and 1980s, and, later on, these agents were introduced into clinical practice [17]. The chemical structure of fluoroquinolones includes a common bicyclic quinolone ring; however, throughout the past decades, different substituents have been added to this common quinolone ring to achieve better tissue penetration and improved antibacterial efficacy [17].

Nalidixic acid and oxalinic acid are quinolone agents which lack the fluorine atom in their chemical structure. These agents were applied in clinical practice in the 1960s to treat urinary tract infections. However, these quinolone agents represented a narrow spectrum antibacterial activity, and nowadays these agents are not recommended for therapy [18].

Structural modifications through the addition of substituents on certain part of the quinolone ring yielded increased potency of agents, namely in terms of pharmacokinetic features and antibacterial spectrum. The most important substituents on the basic quinolone ring are a cyclopropyl or difluorophenyl in position $\mathrm{C} 1$, a fluorine in position $\mathrm{C} 6$, a halogen, methoxy, or fused third ring in position $\mathrm{C} 8$, and a piperazine in position C7. Fluoroquinolones targeting both gyrase and topoisomerase IV enzymes have broad-spectrum antibacterial effect [18].

These structural modifications of fluoroquinolones resulted in the development of various fluoroquinolone agents, namely norfloxacin, ofloxacin, ciprofloxacin, levofloxacin, and moxifloxacin $[17,18]$. Norfloxacin, ofloxacin, and ciprofloxacin have antibacterial effects against gram-negative bacteria, while levofloxacin (a stereoisomer of ofloxacin) is active against gram-negative and gram-positive bacteria. Moxifloxacin is mainly active against gram-positive pathogenic bacteria [18].

Fluoroquinolones have been applied to treat various bacterial infections, including urinary tract, respiratory tract, and enteric infections. However, human pathogen bacteria can develop resistance to fluoroquinolones through various mechanisms. The main mechanism of fluoroquinolone resistance is the accumulation of mutations in gyrase- and topoisomerase IV-coding genes (referred as quinolone-resistance-determining regions/QRDR) [19,20]. Additionally, in gram-negative pathogens, plasmid-mediated quinolone resistance (PMQR) determinants enhance development of fluoroquinolone resistance. PMQRs are represented by Qnr determinants, QepA and OqxAB efflux pumps, and aminoglycoside-acetyltransferase $\mathrm{Ib}-\mathrm{c}$ variants [21-23].

Based on widespread fluoroquinolone resistance, the clinical use of earlier fluoroquinolones has been limited [24,25]. However, new developments in fluoroquinolones have resulted in novel chemical structures and improved antibacterial efficacy.

\section{Delafloxacin}

Delafloxacin (former terms were ABT-492, $R X-3341$, and WQ-3034) is currently the only available anionic (non-zwitterionic) fluoroquinolone which targets both bacterial DNA gyrase and topoisomerase IV enzymes of gram-positive and gram-negative bacteria with equal affinity [26-28]. Its chemical structure is 1-(6-amino-3,5-difluoro-2-pyridinyl)-8chloro-6-fluoro-7-(3-hydroxy-1-azetidinyl)-4-oxo-1,4-dihydro-3-quinolinecarboxylate [18] 
(Figure 1). It has a special chemical structure which makes it a weak acid. It stays uncharged by acidic $\mathrm{pH}$, which aids its transmembrane transfer into the bacterial cell, where it accumulates. In intracellular space (neutral $\mathrm{pH}$ ), it maintains its anionic deprotonated appearance and concentration-dependent antimicrobial activity [16,29]. Based on this unique anionic property, it has an increased antibacterial effect in acidic (inflammatory) environments, for example, in phagolysosomes; in biofilm, as well as in skin; in soft tissue; and in abscesses. Additionally, it has a heteroaromatic substitution which provides a larger molecular surface, and a chlorine atom, which enhances its efficacy against anaerobic bacteria and provides strong polarity. This larger molecular surface can enhance antibacterial activity against strains that are resistant to commonly used fluoroquinolones [24,29,30] (Figure 1).

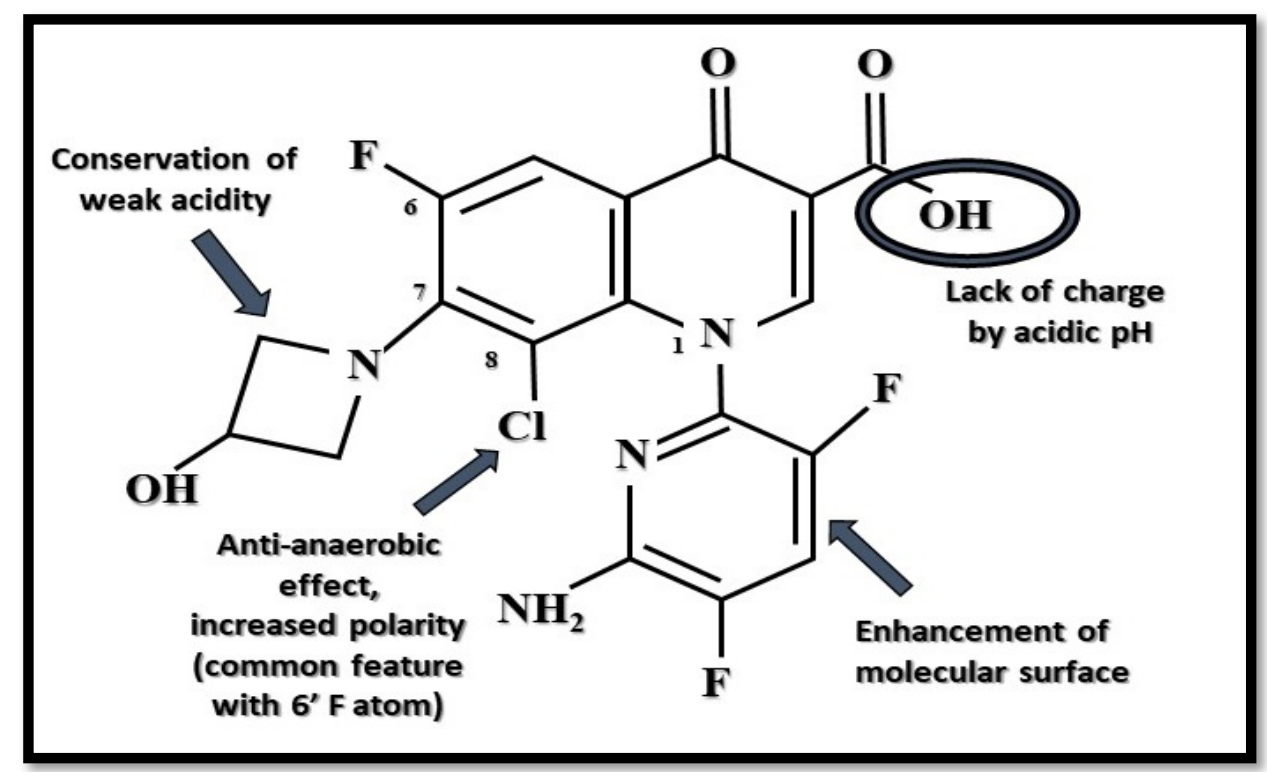

Figure 1. Unique anionic structure of delafloxacin by acidic $\mathrm{pH}$. Arrows show the function of the given substituents. In the position N1, a heteroaromatic substituent provides a larger molecular surface than that of other fluoroquinolones (Figure was created by Dániel Gulyás).

Delafloxacin is a bactericidal agent, and it can be given per os or by intravenous infusion; switch dosing is also accepted. By oral therapy, a $450 \mathrm{mg}$ dose is needed in order to reach a corresponding concentration-time profile, compared to an intravenous $300 \mathrm{mg}$ dose. In rare cases, oral bioavailability (58.8\%) can be decreased through pharmacological interactions with other medications that contain multivalent metal cations, such as $\mathrm{Al}^{3+}, \mathrm{Mg}^{2+}, \mathrm{Fe}^{2+}$, or $\mathrm{Zn}^{2+}$, because of chelation effects [29,31]. In addition, delafloxacin does not inhibit cytochrome P450 isoenzymes; consequently, it does not cause clinically relevant drug-drug interactions with most commonly used medications. Delafloxacin did not show potential synergistic or antagonistic effects with other antibiotics $[16,24,32]$. Plasma protein binding of delafloxacin is approximately $84 \%$ [24]. Patients with kidney failure received a higher dose of this antibiotic, but its activity was not significantly affected by hepatic impairment $[32,33]$.

All known fluoroquinolones may provoke several side effects, such as tendinitis, tendon rupture, photosensitivity, neurological symptoms, and exacerbations of myasthenia gravis, with muscle weakness and QT interval prolongation. In the case of delafloxacin, the FDA has reported peripheral neuropathy, hypersensitivity, and Clostridium difficileassociated diarrhea as possible, but less severe compared to other fluoroquinolones, dosedependent adverse effects. Of these symptoms, the most frequent treatment-emergent adverse effects (TEAEs) were diarrhea, vomiting, and infusion site extravasation. As uncommon complications, hyperglycemic episodes (one patient of ten was affected) and serious elevation of transaminase enzymes (in one patient of twenty-two) were mentioned in these studies. On the other hand, they also demonstrated a lack of photosensitivity and cardiotoxicity, so all in all it appears to be a well-tolerated antibiotic [16,24,30,34-37]. 
Delafloxacin is not recommended during pregnancy, although side effects during lactation and teratogenic effects of delafloxacin were not found in animal studies. It is also contraindicated for pediatric use [16,30].

Delafloxacin has a broad antibacterial spectrum, both in vitro and in vivo, against a wide range of bacteria: gram-positive cocci (staphylococci, including methicillin-resistant S. aureus (MRSA) and methicillin-sensitive S. aureus (MSSA) isolates, streptococci, and enterococci), gram-negatives (e.g., P.aeruginosa, Acinetobacter sp., Haemophilus influenzae, Moraxella catarrhalis, extended-spectrum beta-lactamase (ESBL) producing Escherichia coli and K. pneumoniae, Neisseria gonorrhoeae, and Helicobacter pylori), anaerobes (e.g., Bacteroides fragilis), and causative agents of atypical pneumonia, including Legionella pneumophila, Chlamydia pneumoniae, and Mycoplasma pneumoniae [26,27,38-42]. Based on this broad spectrum of antibacterial activity, current guidelines approved delafloxacin for treatment of adults' acute bacterial skin and skin-structure infections (ABSSSI), as well as community-acquired bacterial pneumonia (CABP) [43-45] (Tables 1-3). According to its antipseudomonal effect, delafloxacin is also a promising agent to treat fluoroquinolone-resistant P.aeruginosa lung infections in patients with cystic fibrosis. Furthermore, the enhanced antibacterial efficacy of delafloxacin in acidic environment enables it for therapeutic use against $H$. pylori infections $[42,46]$.

Compared to the other group members, delafloxacin has increased stability against bacterial gene mutations of DNA gyrase ( $g y r A$ and $g y r B$ ) and topoisomerase IV ( $g r l A$ and $g r l B$ in gram-positive bacteria; par $C$ and parE in gram-negatives) [30]. Based on the double-targeting feature of these enzymes, double- or triple-point mutations of QRDR are required for development of resistance. Interestingly, resistance selection studies were performed, and delafloxacin-resistant strains were selected out from previously susceptible MRSA isolates, by development of mutations in gyrA or gyrB [26,47]. Moreover, delafloxacin-resistant MRSA clinical isolates were obtained from healthcare-associated infections in seven hospitals in Brooklyn (New York) [48]. Delafloxacin-resistant gramnegative pathogens were also reported, and strains exhibiting high-level ciprofloxacin resistance tended to also show delafloxacin resistance. Ciprofloxacin and delafloxacinresistant E. coli, Enterobacter spp., P. aeruginosa, and A. baumannii were identified [28]. In the case of $N$. gonorrhoeae, a selection of delafloxacin-resistant mutants was performed. In the delafloxacin-resistant strains, QRDR mutations were associated with upregulation of MtrC-, MtrD, MtrE-, and NorM-efflux pumps [39].

Table 1. Comparison of the clinically relevant features of novel fluoroquinolones.

\begin{tabular}{|c|c|c|c|c|}
\hline $\begin{array}{c}\text { Novel } \\
\text { Fluoroquinolones }\end{array}$ & Delafloxacin & Finafloxacin & Zabofloxacin & Reference \\
\hline Chemical structure & $\begin{array}{c}\text { Unique anionic } \\
\text { (non-zwitterionic) } \\
\text { structure, with special } \\
\text { substituents and } \\
\text { augmented polarity. }\end{array}$ & $\begin{array}{l}\text { Zwitterionic chemical } \\
\text { structure of } \\
\text { fluoroquinolones } \\
\text { supplemented with } \\
\text { substituents. }\end{array}$ & $\begin{array}{l}\text { Zwitterionic chemical } \\
\text { structure of fluoroquinolones } \\
\text { supplemented with } \\
\text { substituents (two forms are } \\
\text { available). }\end{array}$ & {$[16,18,29]$} \\
\hline Bioavailability & $58.8 \%$ & $75 \%$ (by oral use) & No data available. & {$[29,31]$} \\
\hline Protein binding & Approximately $84 \%$ & No data available. & No data available. & [24] \\
\hline Mechanism of action & $\begin{array}{l}\text { Dual-targeting of DNA } \\
\text { gyrase and } \\
\text { topoisomerase IV } \\
\text { enzymes of } \\
\text { gram-positives and } \\
\text { gram-negatives with } \\
\text { equal affinity. } \\
\text { Increased bactericidal } \\
\text { effect in acidic pH }\end{array}$ & $\begin{array}{l}\text { Dual-targeting (weaker } \\
\text { effect compared to other } \\
\text { group members) of DNA } \\
\text { gyrase and } \\
\text { topoisomerase IV } \\
\text { enzymes of } \\
\text { gram-positives and } \\
\text { gram-negatives with } \\
\text { equal affinity. } \\
\text { Increased bactericidal } \\
\text { effect in acidic } p H .\end{array}$ & $\begin{array}{l}\text { Dual-targeting of DNA } \\
\text { gyrase and topoisomerase IV } \\
\text { enzymes, predominantly of } \\
\text { community-acquired } \\
\text { respiratory tract pathogen } \\
\text { gram-positives, and some } \\
\text { gram-negatives. } \\
\text { Ineffective against major } \\
\text { nosocomial gram-negatives. }\end{array}$ & [26-28,49,50] \\
\hline
\end{tabular}


Table 1. Cont.

\begin{tabular}{|c|c|c|c|c|}
\hline $\begin{array}{c}\text { Novel } \\
\text { Fluoroquinolones }\end{array}$ & Delafloxacin & Finafloxacin & Zabofloxacin & Reference \\
\hline $\begin{array}{l}\text { Approved } \\
\text { Indication }\end{array}$ & $\begin{array}{l}\text { Acute bacterial skin and } \\
\text { skin-structure infections } \\
\text { (ABSSSI) of adults caused } \\
\text { by MRSA, MSSA, } \\
\text { S.haemolyticus, S. } \\
\text { lugdunensis, } \\
\text { S. agalactiae, } \\
\text { Streptococcus anginosus } \\
\text { Group, } \\
\text { S. pyogenes, } \\
\text { E. faecalis, E. coli, E. } \\
\text { cloacae, K.pneumoniae, and } \\
\text { P.aeruginosa. } \\
\text { Community-Acquired } \\
\text { Bacterial Pneumonia of } \\
\text { adults caused by } \\
\text { S.pneumoniae, MSSA, } \\
\text { K. pneumoniae, } \\
\text { P.aeruginosa, } \\
\text { H. influenzae, } H . \\
\text { parainfluenzae, C. } \\
\text { pneumoniae, L. } \\
\text { pneumophila, and } M . \\
\text { pneumoniae. }\end{array}$ & $\begin{array}{l}\text { Otic suspension for acute } \\
\text { otitis externa caused by } P \text {. } \\
\text { aeruginosa and } S \text {. aureus } \\
\text { in patients age one year } \\
\text { and older. }\end{array}$ & $\begin{array}{l}\text { Oral administration for acute } \\
\text { bacterial exacerbation of } \\
\text { chronic obstructive } \\
\text { pulmonary disease (COPD). }\end{array}$ & {$[18,43-45,51]$} \\
\hline
\end{tabular}

Table 2. Other features of novel fluoroquinolones.

\begin{tabular}{|c|c|c|c|c|}
\hline $\begin{array}{c}\text { Novel } \\
\text { Fluoroquinolones }\end{array}$ & Delafloxacin & Finafloxacin & Zabofloxacin & Reference \\
\hline $\begin{array}{l}\text { Further possible } \\
\text { clinical applications }\end{array}$ & $\begin{array}{l}\text { P. aeruginosa-mediated lung } \\
\text { infections in patients with } \\
\text { cystic fibrosis. } \\
\text { Infection by } \\
\text { multidrug-resistant H.pylori. }\end{array}$ & $\begin{array}{c}\text { Complicated and } \\
\text { non-complicated } \\
\text { urinary-tract infections. } \\
\text { Zoonoses, e.g., Y.pestis and } \\
\text { B.anthracis. } \\
\text { Prophylaxis and treatment } \\
\text { of B. pseudomallei } \\
\text { infections. }\end{array}$ & $\begin{array}{l}\text { Community-acquired } \\
\text { bacterial pneumonia. }\end{array}$ & {$[18,42,46,50]$} \\
\hline $\begin{array}{c}\text { Contraindication } \\
\text { and } \\
\text { side effects }\end{array}$ & $\begin{array}{c}\text { Well-tolerated; lack of } \\
\text { teratogenic effect, } \\
\text { photosensitivity and } \\
\text { cardiotoxicity. } \\
\text { Diarrhoea, vomiting and } \\
\text { other } \\
\text { fluoroquinolone-specific } \\
\text { adverse affects may occur. }\end{array}$ & $\begin{array}{l}\text { Ophthalmic use is } \\
\text { contraindicated. } \\
\text { In animal studies, showed } \\
\text { teratogenic ability and } \\
\text { fluoroquinolone-specific } \\
\text { adverse effects (per os). } \\
\text { Hypersensitivity and } \\
\text { pruritus. }\end{array}$ & $\begin{array}{l}\text { Well-tolerated; lack of long } \\
\text { QT-syndrome; in animal } \\
\text { studies, subacute toxicity } \\
\text { (atrophy of endocrine } \\
\text { organs with vomitus by } \\
\text { dogs) was found. } \\
\text { Mainly gastrointestinal } \\
\text { adverse effects were } \\
\text { reported. }\end{array}$ & $\begin{array}{c}{[16,18,24,30,} \\
34-37,51]\end{array}$ \\
\hline $\begin{array}{l}\text { Resistance } \\
\text { mechanisms }\end{array}$ & $\begin{array}{c}\text { Multiple mutations by } \\
\text { bacterial topoisomerase IV } \\
\text { enzymes. } \\
\text { Single mutations with efflux } \\
\text { pumps. } \\
\text { Generally } \\
\text { fluoroquinolone-resistant } \\
\text { strains are susceptible to to } \\
\text { Delafloxacin (cross-resistance } \\
\text { is also known). }\end{array}$ & $\begin{array}{l}\text { Multiple mutations in } \\
\text { bacterial topoisomerase IV } \\
\text { enzymes. } \\
\text { Cross-resistance with other } \\
\text { fluoroquinolones was } \\
\text { reported. }\end{array}$ & $\begin{array}{c}\text { Multiple mutations in } \\
\text { bacterial Topoisomerase IV } \\
\text { enzymes. } \\
\text { Generally } \\
\text { fluoroquinolone-resistant } \\
\text { strains are susceptible to } \\
\text { Zabofloxacin. }\end{array}$ & $\begin{array}{l}{[18,26,28,30,} \\
39,47,48,51]\end{array}$ \\
\hline
\end{tabular}


Table 3. MIC values of novel fluoroquinolones in the case of ESKAPE group members and other pathogens. For finafloxacin the table contains values in slightly acidic $\mathrm{pH}$ (5.8-6.2), and for zabofloxacin it demonstrates values of fluoroquinoloneresistant MRSA strains.

\begin{tabular}{|c|c|c|c|c|c|c|c|}
\hline \multirow{2}{*}{$\begin{array}{l}\text { Novel Fluoro- } \\
\text { quinolones }\end{array}$} & \multicolumn{2}{|c|}{ Delafloxacin } & \multicolumn{2}{|c|}{ Finafloxacin } & \multicolumn{2}{|c|}{ Zabofloxacin } & \multirow{2}{*}{ Reference } \\
\hline & $\mathrm{MIC}_{90}(\mathrm{mg} / \mathrm{L})$ & MIC Range & $\mathrm{MIC}_{90}(\mathrm{mg} / \mathrm{L})$ & MIC Range & $\mathrm{MIC}_{90}(\mathrm{mg} / \mathrm{L})$ & MIC Range & \\
\hline E. faecalis & 1 & $\leq 0.004$ to 2 & 16 & $0.25-16$ & 2 & $0.008 \geq 4$ & {$[18,24,38,52]$} \\
\hline E. faecium & $>4$ & 0.008 to $>4$ & $\begin{array}{c}\text { No data } \\
\text { available. }\end{array}$ & $0.5-32$ & 16 & $2-32$ & {$[18,24,38,52]$} \\
\hline MRSA & 0.5 & \multirow{2}{*}{$\leq 0.004$ to 4} & 0.125 & $0.06-0.125$ & 32 & $0.016-0.64$ & {$[18,24,38,52]$} \\
\hline MSSA & 0.008 & & \multicolumn{2}{|c|}{ No data available. } & \multicolumn{2}{|c|}{ No data available. } & {$[24,38]$} \\
\hline E. coli & \multirow{4}{*}{$>4$} & 0.008 to $>4$ & 32 & $2-64$ & \multirow{2}{*}{1} & $0.015-64$ & {$[18,24,38,52]$} \\
\hline K.pneumoniae & & 0.06 to $>4$ & 0.5 & $0.008-1$ & & $0.06-8$ & {$[24,38,52]$} \\
\hline P. aeruginosa & & \multirow[b]{2}{*}{0.015 to $>4$} & 2 & $0.25-8$ & 8 & $0.125-32$ & {$[24,38,52]$} \\
\hline $\begin{array}{l}\text { A. baumannii/ } \\
\text { A. calcoaceticus }\end{array}$ & & & \multicolumn{2}{|c|}{ No data available. } & 4 & $0.008-8$ & [30] \\
\hline S. maltophilia & 2 & $0.12-16$ & 1 & $0.125-16$ & No data & ailable. & {$[30,52]$} \\
\hline
\end{tabular}

\section{Finafloxacin}

Finafloxacin (former term: BAY35-3377) has a zwitterionic chemical structure with a chiral cyano-substituent and pyrrolo-oxazinyl component [18] (Figure 2). Based on this chemical construction, it is characterized by the dual inhibition of both DNA gyrase and topoisomerase IV enzymes, which leads to broad-spectrum antibacterial activity $[49,50]$.

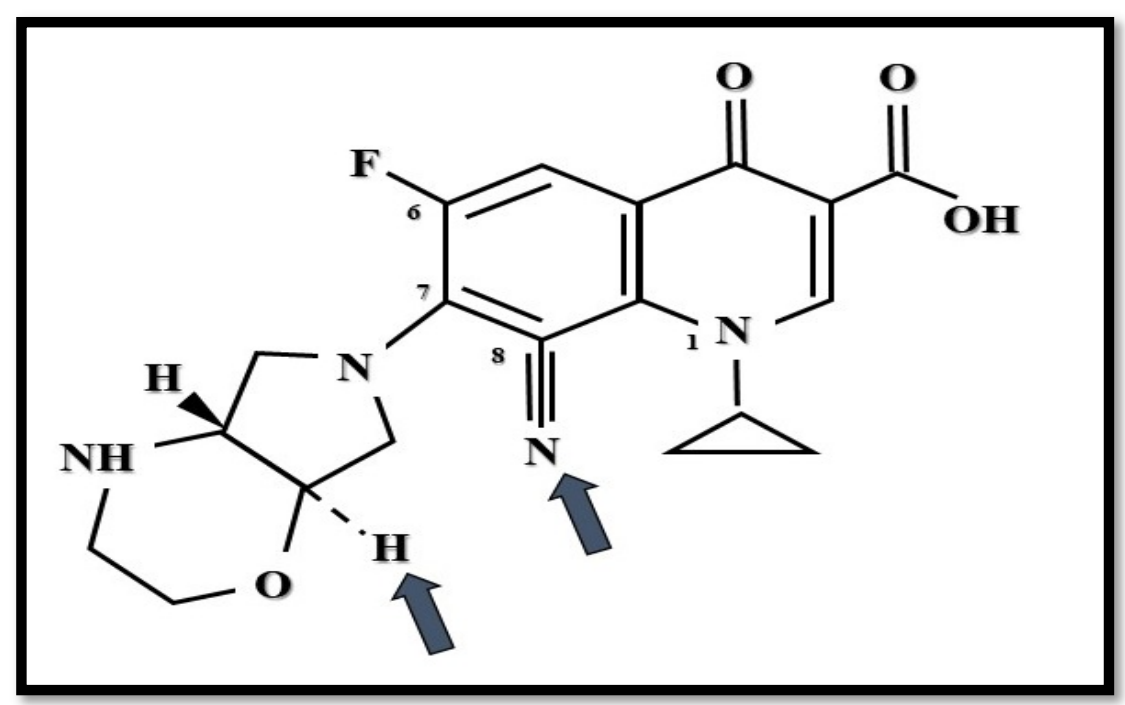

Figure 2. Structure of finafloxacin. Arrows show novel substituents compared to other fluoroquinolones (Figure was created by Dániel Gulyás).

Finafloxacin shows increased antibacterial activity in acidic environments (e.g., in an infection site), although in neutral $\mathrm{pH}$ it possesses a similar bactericidal effect compared to other clinically used fluoroquinolones [49].

Although the FDA primarily indicated finafloxacin as a $0.3 \%$ otic suspension for therapy of acute otitis externa, caused by P. aeruginosa and S. aureus, in patients aged one year and older, [51] finafloxacin has remarkable antibacterial efficacy against major gram-negative bacteria, including fluoroquinolone-resistant Enterobacteriaceae, A.baumannii, and L. pneumophila. Major gram-positive pathogens show finafloxacin susceptibility, for example, MRSA and un-phagocytized Listeria monocytogenes [52-54].

Evaluation of the pharmacokinetic parameters of finafloxacin showed that, after oral doses (400 to $800 \mathrm{mg}$ ), it reached higher concentrations in urine than the measured 
MIC values of the most important causative agents of complicated UTIs, including E.coli, P.aeruginosa, and even fluoroquinolone-resistant uropathogens. In this case, bioavailability reached $75 \%$ [55-57]. Based on these results, many studies suggest finafloxacin as a suitable antibiotic for therapy of difficult-to-treat UTIs in the future [50,55-58]. Furthermore, because of its $\mathrm{pH}$-related activity, it has a strong effect against intracellular pathogens (e.g., Coxiella burnetii [59], Burkholderia pseudomallei, Yersinia pestis, Francisella tularensis, and Bacillus anthracis). These are causative agents of severe zoonotic diseases [60-62]. According to different studies, finafloxacin was also able to overcome the efflux-pumps of fluoroquinolone-resistant B. pseudomallei strains, so it is a potential antibiotic for melioidosis prophylaxis and therapy [63-65] (Table 2).

Due to these favorable features, despite the well-known adverse effects of oral fluoroquinolones, finafloxacin appeared as a teratogenic antimicrobial agent in animal studies. As an eardrop, allergic reactions and pruritus may also occur. Based on this local form of clinical use, only a minimal concentration was detected in blood; consequently, relevant drug-drug interactions were not found. Cross-resistance between finafloxacin and the earlier generations of fluoroquinolones was also observed. Mainly, the chromosomal mutations of QRDR and drug efflux mechanisms play an important role in development of resistance against this novel antibiotic [51].

\section{Zabofloxacin}

Zabofloxacin (DW-224a) is an orally administered broad-spectrum fluoroquinolone (fluoronaphthyridone) that targets both DNA gyrase and topoisomerase IV enzymes. Its chemical structure is \{1-cyclopropyl-6-fluoro-7-[8-(methoxyimino)-2,6-diazaspiro[3,4]oct-6yl]-4oxo-1,4-dihydro[1,8]naphthyridine-3-carboxylic acid hydrochloride\} (Figure 3). There are two forms of zabofloxacin available: zabofloxacin hydrochloride (DW-224a) and aspartate (DW-224aa) $[66,67]$.

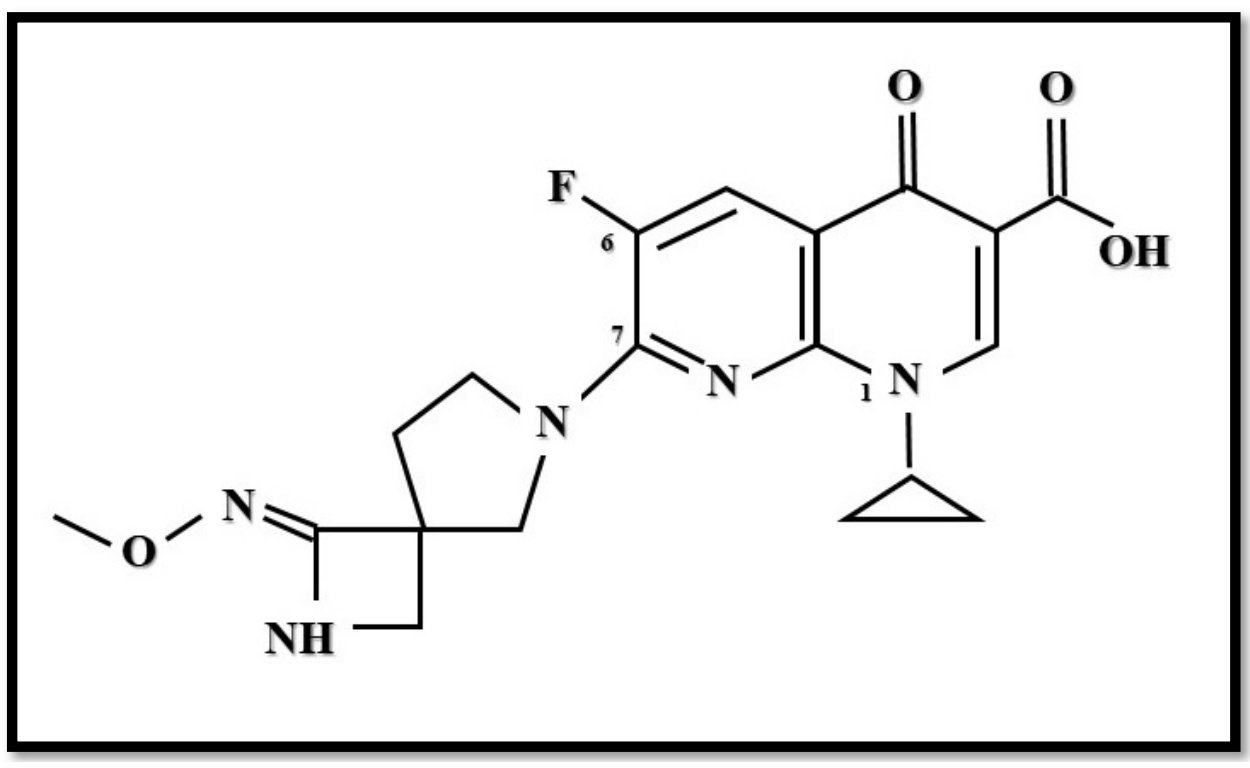

Figure 3. Structure of zabofloxacin (Figure was created by Dániel Gulyás).

Zabofloxacin was approved for clinical use in South Korea, the Middle-East, and North-African countries $[68,69]$. The indication of zabofloxacin is in treatment of patients with acute bacterial exacerbation of chronic obstructive pulmonary disease.

Zabofloxacin demonstrates bactericidal effects against major respiratory tract pathogens, namely Streptococcus pneumoniae, Staphylococcus aureus, Haemophilus influenzae, and Moraxella catarrhalis. Furthermore, zabofloxacin showed bactericidal effects against Neisseria gonorhoeae, as well as against fluoroquinolone-resistant $S$. aureus. Additionally, zabofloxacin was equally effective against Klebsiella pneumoniae compared to moxifloxacin. However, zabofloxacin 
lacks potency against major nosocomial gram-negative pathogens, namely Pseduomonas aeruginosa and Acinetobacter baumannii [66,70-73] (Table 3).

Zabofloxacin was found to be a well-tolerated agent in healthy male volunteers. Among the detected adverse events were nausea (7\% of individuals), hypotension (3\%), somnolence (3\%), and increase of blood phosphokinase (3\%) [74].

Several clinical studies were conducted to test the antibacterial efficacy and pharmacokinetic profile of zabofloxacin. A phase one clinical trial investigated the pharmacokinetic profile of $183 \mathrm{mg}$ and $367 \mathrm{mg}$ zabofloxacin, compared to $250 \mathrm{mg}$ levofloxacin (ClinicalTrials.gov identifier: NCT02212795). The pharmacokinetic characteristics of zabofloxacin hydrochloride (DW224a) and zabofloxacin aspartate (DW-224aa) were investigated in a phase one clinical trial (ClinicalTrials.gov identifier: NCT01341249). A phase three clinical trial was conducted to compare $367 \mathrm{mg}$ zabofloxacin with $400 \mathrm{mg}$ moxifloxacin in therapeutic use (ClinicalTrials.gov identifier: NCT01658020). A phase two clinical trial was also organized to test the safety and efficacy of zabofloxacin in community acquired pneumonia, but this trail was terminated. No results were posted (ClinicalTrials.gov identifier: NCT01081964). Zabofloxacin hydrochloride and zabofloxacin aspartate were analyzed in the phase one clinical trial. A total of twenty-nine healthy male individuals were enrolled in a random, open-label single-dose study, and pharmacokinetic characteristics were investigated. During this trial, orally-administered $366.7 \mathrm{mg}$ zabofloxacin hydrochloride and $366.5 \mathrm{mg}$ zabofloxacin aspartate were analyzed. The peak serum concentration $\left(\mathrm{C}_{\max }\right)$ values were $1.9 \pm 0.5 \mathrm{mg} / \mathrm{L}$ and $2 \pm 0.3 \mathrm{mg} / \mathrm{L}$, and these values were reached between $0.5-4 \mathrm{~h}$ and $0.8-3 \mathrm{~h}$, respectively. The half-life time of zabofloxacin was $8 \pm 1 \mathrm{~h}$ for both formulations [74]. The toxicity of zabofloxacin hydrochloride $(366.7 \mathrm{mg})$ and zabofloxacin aspartate $(366.5 \mathrm{mg})$ was also investigated. Both formulations were well tolerated in healthy male individuals in a phase one clinical trial. Only some adverse events were recorded; notably, nausea, hypotension, somnolence, and increased blood phosphokinase. However, prolongation of QT intervals was not detected [74]. The efficacy of oral zabofloxacin (367 mg once daily for 5 days) was compared with moxifloxacin (400 mg once daily for 7 days) in a phase three, multicenter, double-blinded, randomized non-inferiority clinical trial [75]. In this study, a total of 345 patients diagnosed with chronic obstructive pulmonary disease, with moderate exacerbations, were included. The overall clinical cure rates were $88.2 \%$, for zabofloxacin, and $89.1 \%$ for moxifloxacin. There was no statistically significant difference $(p=0.89)$ detected. According to this clinical trial, zabofloxacin reaches equal clinical outcome, compared to that of moxifloxacin, by the end point of the test period. The antibacterial efficacy of zabofloxacin was compared with that of moxifloxacin, in a patient group suffering from lower-respiratory-tract infections, without chronic bronchitis. In this study, $85.9 \%$ and $84.2 \%$ cure rates were observed, respectively, and no statistically significant differences were reported $(p=0.76)$ [75].

\section{Conclusions}

Nowadays, antibiotic-resistant bacteria can cause severe infections, including nosocomial and community-acquired diseases. The ease with which human pathogen bacteria develop resistance against commonly used antibiotics is worrisome. Rapid dissemination of antibiotic-resistant bacteria is detected all over the world, and infections caused by these bacteria are associated with high mortality rates. Thus, therapy of these infections is a great challenge worldwide. The number of available effective antimicrobial agents is limited. In the last few years, some novel antimicrobial agents were introduced into clinical practice, but further developments are still required [10].

Three new fluoroquinolones, delafloxacin, finafloxacin, and zabofloxacin, have special chemical structures which lead to many favorable properties; for example, broad antibacterial spectrums, good tissue penetration, and the lack of severe adverse effects. On the other hand, development of resistance against these new fluoroquinolones can occur; therefore, the prudent use of antibiotics is necessary. These new agents are only approved to treat certain infections, such as adults' acute bacterial skin and skin-structure infections, 
community-acquired pneumonia, and P. aeruginosa related acute otitis externa or acute bacterial exacerbation of chronic obstructive pulmonary disease. Since their first clinical use, new studies have recommended other possible indications for these antibiotics, which can further enlarge their clinical applications. These further possible indications include the treatment of urinary-tract infections and lower-respiratory-tract infections. However, in the meantime, some delafloxacin-resistant $S$. aureus clinical isolates were also reported [48], as well as reports of delafloxacin-resistant E.coli, Enterobacter spp., P. aeruginosa, and $A$. baumannii [28]. These are alarming cases, and indicate a stronger need for the prudent use of antibiotics.

In summary, the introduction of novel antimicrobial agents provides new options to treat infections caused by bacteria that are already resistant to commonly used antibiotics. Continuous monitoring of the development of resistance against these novel antibiotics is necessary, and the prudent use of antibiotics is also important for successful treatment in the future.

Author Contributions: B.K., writing — original draft preparation; D.G., figures, review, and editing; D.S., supervision. All authors have read and agreed to the published version of the manuscript.

Funding: This research received no external funding.

Conflicts of Interest: The authors declare no conflict of interest.

\section{References}

1. Zhen, X.; Lundborg, C.S.; Sun, X.; Hu, X.; Dong, H. Economic burden of antibiotic resistance in ESKAPE organisms: A systematic review. Antimicrob. Resist. Infect. Control. 2019, 8, 137. [CrossRef] [PubMed]

2. Grundmann, H.; Glasner, C.; Albiger, B.; Aanensen, D.M.; Tomlinson, C.T.; Andrasević, A.T.; Cantón, R.; Carmeli, Y.; Friedrich, A.W.; Giske, C.G.; et al. European survey of carbapenemase-producing enterobacteriaceae (EuSCAPE) working group. Occurrence of carbapenemase-producing Klebsiella pneumoniae and Escherichia coli in the European survey of carbapenemase-producing Enterobacteriaceae (EuSCAPE): A prospective, multinational study. Lancet Infect. Dis. 2017, 17, 153-163. [PubMed]

3. David, S.; Reuter, S.; Harris, S.R.; Glasner, C.; Feltwell, T.; Argimon, S.; Abudahab, K.; Goater, R.; Giani, T.; Errico, G.; et al. Epidemic of carbapenem-resistant Klebsiella pneumoniae in Europe is driven by nosocomial spread. Nat. Microbiol. 2019, 4, 1919-1929. [CrossRef]

4. Boucher, H.W.; Talbot, G.H.; Bradley, J.S.; Edwards, J.E.; Gilbert, D.; Rice, L.B.; Scheld, M.; Spellberg, B.; Bartlett, J. Bad bugs, no drugs: No ESKAPE! An update from the infectious diseases society of America. Clin. Infect. Dis. 2009, 48, 1-12. [CrossRef]

5. Bassetti, M.; Vena, A.; Croxatto, A.; Righi, E.; Guery, B. How to manage Pseudomonas aeruginosa infections. Drugs Context. 2018, 7, 212527. [CrossRef]

6. Livermore, D.M. Has the era of untreatable infections arrived? J. Antimicrob. Chemother. 2009, 64 (Suppl. S1), i29-i36. [CrossRef] [PubMed]

7. Oliver, A.; Mulet, X.; López-Causapé, C.; Juan, C. The increasing threat of Pseudomonas aeruginosa high-risk clones. Drug Resist. Updates 2015, 21-22, 41-59. [CrossRef] [PubMed]

8. Botelho, J.; Grosso, F.; Peixe, L. Antibiotic resistance in Pseudomonas aeruginosa Mechanisms, epidemiology and evolution. Drug Resist. Updates 2019, 44, 26-47. [CrossRef]

9. Tacconelli, E.; Carrara, E.; Savoldi, A.; Harbarth, S.; Mendelson, M.; Monnet, D.L.; Pulcini, C.; Kahlmeter, G.; Kluytmans, J.; Carmeli, Y.; et al. Discovery, research, and development of new antibiotics: The WHO priority list of antibiotic-resistant bacteria and tuberculosis. Lancet Infect. Dis. 2018, 18, 318-327. [CrossRef]

10. Butler, M.S.; Paterson, D.L. Antibiotics in the clinical pipeline in October 2019. J. Antibiot. 2020, 73, 329-364. [CrossRef]

11. Saravolatz, L.D.; Stein, G.E. Plazomicin: A new aminoglycoside. Clin. Infect. Dis. 2020, 70, 704-709. [CrossRef] [PubMed]

12. Sato, T.; Yamawaki, K. Cefiderocol: Discovery, chemistry, and in vivo profiles of a novel siderophore cephalosporin. Clin. Infect. Dis. 2019, 69 (Suppl. S7), S538-S543. [CrossRef] [PubMed]

13. Petty, L.A.; Henig, O.; Patel, T.S.; Pogue, J.M.; Kaye, K.S. Overview of meropenem-vaborbactam and newer antimicrobial agents for the treatment of carbapenem-resistant Enterobacteriaceae. Infect. Drug Resist. 2018, 11, 1461-1472. [CrossRef] [PubMed]

14. Bush, K.; Bradford, P.A. Interplay between beta-lactamases and new beta-lactamase inhibitors. Nat. Rev. Microbiol. 2019, 17, 295-306. [CrossRef]

15. Bader, M.S.; Loeb, M.; Leto, D.; Brooks, A.A. Treatment of urinary tract infections in the era of antimicrobial resistance and new antimicrobial agents. Postgrad. Med. 2020, 132, 234-250. [CrossRef] [PubMed]

16. US Food and Drug Administration. BAXDELA (Delafloxacin) Prescribing Information and Medication Guide. Available online: https:/ / www.accessdata.fda.gov /drugsatfda_docs/label/2017/208610s000,208611s000lbl.pdf (accessed on 8 December 2018).

17. Rusu, A.; Lungu, I.A.; Moldovan, O.L.; Tanase, C.; Hancu, G. Structural characterization of the millennial antibacterial (fluoro) quinolones-shaping the fifth generation. Pharmaceutics 2021, 13, 1289. [CrossRef] [PubMed] 
18. Kocsis, B.; Domokos, J.; Szabo, D. Chemical structure and pharmacokinetics of novel quinolone agents represented by avarofloxacin, delafloxacin, finafloxacin, zabofloxacin and nemonoxacin. Ann. Clin. Microbiol. Antimicrob. 2016, 15, 34. [CrossRef] [PubMed]

19. Hooper, D.C.; Jacoby, G.A. Topoisomerase inhibitors: Fluoroquinolone mechanisms of action and resistance. Cold Spring Harb. Perspect. Med. 2016, 6, a025320. [CrossRef]

20. Vinué, L.; Sater, M.R.A.; Herriott, I.C.; Huntley, M.H.; Wang, M.; Jacoby, G.A.; Hooper, D.C. Plasmids and genes contributing to high-level quinolone resistance in Escherichia coli. Int. J. Antimicrob. Agents. 2020, 56, 105987. [CrossRef]

21. Rodríguez-Martínez, J.M.; Machuca, J.; Cano, M.E.; Calvo, J.; Martínez-Martínez, L.; Pascual, A. Plasmid-mediated quinolone resistance: Two decades on. Drug Resist. Updates 2016, 29, 13-29. [CrossRef]

22. Kocsis, B.; Szmolka, A.; Szabo, O.; Gulyas, D.; Kristóf, K.; Göcző, I.; Szabo, D. Ciprofloxacin promoted qnrD expression and phylogenetic analysis of $q n r D$ harboring plasmids. Microb. Drug Resist. 2019, 25, 501-508. [CrossRef]

23. Gulyás, D.; Kocsis, B.; Szabó, D. Plasmid copy number and qnr gene expression in selection of fluoroquinolone-resistant Escherichia coli. Acta Microbiol. Immunol. Hung. 2019, 66, 169-178. [CrossRef] [PubMed]

24. Tulkens, P.M.; Van Bambeke, F.; Zinner, S.H. Profile of a novel anionic fluoroquinolone-delafloxacin. Clin. Infect. Dis. 2019, 68 (Suppl. S3), S213-S222. [CrossRef] [PubMed]

25. European Medicines Agency (EMA). Quinolone- and Fluoroquinolone-Containing Medicinal Products: Disabling and Potentially Permanent Side Effects Lead to Suspension or Restrictions of Quinolone and Fluoroquinolone Antibiotics. Available online: https: //www.ema.europa.eu/en/medicines/human/referrals/quinolone-fluoroquinolone-containing-medicinal-products (accessed on 8 December 2018).

26. Nilius, A.M.; Shen, L.L.; Hensey-Rudloff, D.; Almer, L.S.; Beyer, J.M.; Balli, D.J.; Cai, Y.; Flamm, R.K. In vitro antibacterial potency and spectrum of ABT-492, a new fluoroquinolone. Antimicrob. Agents Chemother. 2003, 47, 3260-3269. [CrossRef] [PubMed]

27. Harnett, S.J.; Fraise, A.P.; Andrews, J.M.; Jevons, G.; Brenwald, N.P.; Wise, R. Comparative study of the in vitro activity of a new fluoroquinolone, ABT-492. J. Antimicrob. Chemother. 2004, 53, 783-792. [CrossRef] [PubMed]

28. Almer, L.S.; Hoffrage, J.B.; Keller, E.L.; Flamm, R.K.; Shortridge, V.D. In vitro and bactericidal activities of ABT-492, a novel fluoroquinolone, against Gram-positive and Gram-negative organisms. Antimicrob. Agents Chemother. 2004, 48, 2771. [CrossRef]

29. Saravolatz, L.D.; Stein, G.E. Delafloxacin: A new anti-methicillin-resistant Staphylococcus aureus Fluoroquinolone. Clin. Infect. Dis. 2019, 68, 1058-1062. [CrossRef]

30. Mogle, B.T.; Steele, J.M.; Thomas, S.J.; Bohan, K.B.H.; Kufel, W.D. Clinical review of delafloxacin: A novel anionic fluoroquinolone. J. Antimicrob. Chemother. 2018, 73, 1439-1451. [CrossRef]

31. Hoover, R.; Hunt, T.; Benedict, M.; Paulson, S.K.; Lawrence, L.; Cammarata, S.; Sun, E. Safety, tolerability, and pharmacokinetic properties of intravenous delafloxacin after single and multiple doses in healthy volunteers. Clin. Ther. 2016, 38, 53-65. [CrossRef]

32. Hoover, R.; Marbury, T.C.; Preston, R.A.; Quintas, M.; Lawrence, L.E.; Paulson, S.K.; Luke, R.D.; Cammarata, S.K. Clinical pharmacology of delafloxacin in patients with hepatic impairment. J. Clin. Pharmacol. 2017, 57, 328-335. [CrossRef]

33. Hoover, R.; Lawrence, L.; Smith, C.; Longcor, J. Pharmacokinetics (PK) of delafloxacin (DLX) in patients with varying degrees of renal impairment. In Proceedings of the Fifty-Third Interscience Conference on Antimicrobial Agents and Chemotherapy, Denver, CO, USA, 10-13 September 2013; Poster A-017e. American Society for Microbiology: Washington, DC, USA, 2013.

34. Center for Drug Evaluation and Research: Delafloxacin NDA Briefing. Available online: https://www.accessdata.fda.gov/ drugsatfda_docs/nda/2017/208610Orig1s000,208611Orig1s000Approv.pdf (accessed on 10 September 2021).

35. O'Riordan, W.; Mehra, P.; Manos, P.; Kingsley, J.; Lawrence, L.; Cammarata, S. A randomized Phase 2 study comparing two doses of delafloxacin with tigecycline in adults with complicated skin and skin-structure infections. Int. J. Infect. Dis. 2015, 30, 67-73. [CrossRef] [PubMed]

36. Rubinstein, E.; Camm, J. Cardiotoxicity of fluoroquinolones. J. Antimicrob. Chemother. 2002, 49, 593-596. [CrossRef] [PubMed]

37. Sharma, R.; Sandrock, C.E.; Meehan, J.; Theriault, N. Community-acquired bacterial pneumonia-changing epidemiology, resistance patterns, and newer antibiotics: Spotlight on delafloxacin. Clin. Drug Investig. 2020, 40, 947-960. [CrossRef] [PubMed]

38. Pfaller, M.A.; Sader, H.S.; Rhomberg, P.R.; Flamm, R.K. In vitro activity of delafloxacin against contemporary bacterial pathogens from the United States and Europe, 2014. Antimicrob. Agents Chemother. 2018, 62, e02803-17. [CrossRef] [PubMed]

39. Soge, O.O.; Salipante, S.J.; No, D.; Duffy, E.; Roberts, M.C. In vitro activity of delafloxacin against clinical Neisseria gonorrhoeae isolates and selection of gonococcal delafloxacin resistance. Antimicrob. Agents Chemother. 2016, 60, 3106-3111. [CrossRef] [PubMed]

40. Hammerschlag, M.R.; Roblin, P.M. The in vitro activity of a new fluoroquinolone, ABT-492, against recent clinical isolates of Chlamydia pneumoniae. J. Antimicrob. Chemother. 2004, 54, 281-282. [CrossRef]

41. Waites, K.B.; Crabb, D.M.; Duffy, L.B. Comparative in vitro susceptibilities and bactericidal activities of investigational fluoroquinolone ABT-492 and other antimicrobial agents against human mycoplasmas and ureaplasmas. Antimicrob. Agents Chemother. 2003, 47, 3973-3975. [CrossRef]

42. Boyanova, L.; Markovska, R.; Medeiros, J.; Gergova, G.; Mitov, I. Delafloxacin against Helicobacter pylori, a potential option for improving eradication success? Diagn. Microbiol. Infect. Dis. 2020, 96, 114980. [CrossRef]

43. Melinta Therapeutics. Baxdela (Delafloxacin) Tablets, for Oral Use; Baxdela (Delafloxacin) for Injection, for Intravenous Use: US Prescribing Information. 2019. Available online: https://baxdela.com/docs/baxdela-prescribing-information.pdf (accessed on 16 March 2020). 
44. European Medicines Agency. Quofenix (Delafloxacin): Summary of Product Characteristics. 2019. Available online: https: / / www.ema.europa.eu/ (accessed on 16 March 2020).

45. Scott, L.J. Delafloxacin: A review in acute bacterial skin and skin structure infections. Drugs 2020, 80, 1247-1258. [CrossRef]

46. Millar, B.C.; McCaughan, J.; Rendall, J.C.; Moore, J.E. Delafloxacin-A novel fluoroquinolone for the treatment of ciprofloxacinresistant Pseudomonas aeruginosa in patients with cystic fibrosis. Clin. Respir. J. 2021, 15, 116-120. [CrossRef]

47. Remy, J.M.; Tow-Keogh, C.A.; McConnell, T.S.; Dalton, J.M.; DeVito, J.A. Activity of delafloxacin against methicillin-resistant Staphylococcus aureus: Resistance selection and characterization. J. Antimicrob. Chemother. 2012, 67, 2814-2820. [CrossRef]

48. Iregui, A.; Khan, Z.; Malik, S.; Landman, D.; Quale, J. Emergence of delafloxacin-resistant Staphylococcus aureus in Brooklyn, New York. Clin. Infect. Dis. 2020, 70, 1758-1760. [CrossRef]

49. Patel, H.; Andresen, A.; Vente, A.; Heilmann, H.D.; Stubbings, W.; Seiberling, M.; Lopez-Lazaro, L.; Pokorny, R.; Labischinski, H. Human pharmacokinetics and safety profile of finafloxacin, a new fluoroquinolone antibiotic, in healthy volunteers. Antimicrob. Agents Chemother. 2011, 55, 4386-4393. [CrossRef]

50. Wagenlehner, F.; Nowicki, M.; Bentley, C.; Lückermann, M.; Wohlert, S.; Fischer, C.; Vente, A.; Naber, K.; Dalhoff, A. Explorative randomized phase II clinical study of the efficacy and safety of finafloxacin versus ciprofloxacin for treatment of complicated urinary tract infections. Antimicrob. Agents Chemother. 2018, 62, e02317-17. [CrossRef] [PubMed]

51. US Food and Drug Administration. XTORO Prescribing Information and Medication Guide 2014. Available online: https: //www.accessdata.fda.gov/drugsatfda_docs/label/2014/206307s000lbl.pdf (accessed on 20 August 2021).

52. Stubbings, W.; Leow, P.; Yong, G.C.; Goh, F.; Körber-Irrgang, B.; Kresken, M.; Endermann, R.; Labischinski, H. In vitro spectrum of activity of finafloxacin, a novel, $\mathrm{pH}$-activated fluoroquinolone, under standard and acidic conditions. Antimicrob. Agents Chemother. 2011, 55, 4394-4397. [CrossRef]

53. Lemaire, S.; van Bambeke, F.; Tulkens, P.M. Activity of finafloxacin, a novel fluoroquinolone with increased activity at acid pH, towards extracellular and intracellular Staphylococcus aureus, Listeria monocytogenes and Legionella pneumophila. Int. J. Antimicrob. Agents. 2011, 38, 52-59. [CrossRef] [PubMed]

54. Emrich, N.C.; Heisig, A.; Stubbings, W.; Labischinski, H.; Heisig, P. Antibacterial activity of finafloxacin under different pH conditions against isogenic strains of Escherichia coli expressing combinations of defined mechanisms of fluoroquinolone resistance. J. Antimicrob. Chemother. 2010, 65, 2530-2533. [CrossRef]

55. Dalhoff, A.; Stubbings, W.; Schubert, S. Comparative in vitro activities of the novel antibacterial finafloxacin against selected Gram-positive and Gram-negative bacteria tested in Mueller-Hinton broth and synthetic urine. Antimicrob. Agents Chemother. 2011, 55, 1814-1818. [CrossRef] [PubMed]

56. Vente, A.; Bentley, C.; Lückermann, M.; Tambyah, P.; Dalhoff, A. Early clinical assessment of the antimicrobial activity of finafloxacin compared to ciprofloxacin in subsets of microbiologically characterized isolates. Antimicrob. Agents Chemother. 2018, 62, e02325-17. [CrossRef]

57. Taubert, M.; Lückermann, M.; Vente, A.; Dalhoff, A.; Fuhr, U. Population pharmacokinetics of finafloxacin in healthy volunteers and patients with complicated urinary tract infections. Antimicrob. Agents Chemother. 2018, 62, e02328-17. [CrossRef]

58. Bartoletti, R.; Cai, T.; Perletti, G.; Wagenlehner, F.M.E.; Bjerklund Johansen, T.E. Finafloxacin for the treatment of urinary tract infections. Expert Opin. Investig. Drugs 2015, 24, 957-963. [CrossRef]

59. Peyrusson, F.; Whelan, A.O.; Hartley, M.G.; Norville, I.H.; Harding, S.V.; Van Bambeke, F. Intracellular activity of antibiotics against Coxiella burnetii in a model of activated human THP-1 cells. Antimicrob. Agents Chemother. 2021, 65, e01061-21. [CrossRef]

60. Chalhoub, H.; Harding, S.V.; Tulkens, P.M.; Van Bambeke, F. Influence of pH on the activity of finafloxacin against extracellular and intracellular Burkholderia thailandensis, Yersinia pseudotuberculosis and Francisella philomiragia and on its cellular pharmacokinetics in THP-1 monocytes. Clin. Microbiol. Infect. 2020, 26, 1254.e1-1254.e8. [CrossRef] [PubMed]

61. Barnes, K.B.; Zumbrun, S.D.; Halasohoris, S.A.; Desai, P.D.; Miller, L.L.; Richards, M.I.; Russell, P.; Bentley, C.; Harding, S.V. Demonstration of the broad spectrum in vitro activity of finafloxacin against pathogens of biodefence interest. Antimicrob. Agents Chemother. 2019, 63, e01470-19. [CrossRef]

62. Barnes, K.B.; Hamblin, K.A.; Richards, M.I.; Laws, T.R.; Vente, A.; Atkins, H.S.; Harding, S.V. The fluoroquinolone finafloxacin protects BALB/c Mice against an intranasal infection with francisella tularensis strain SchuS4. Front. Microbiol. 2019, 10, 904. [CrossRef] [PubMed]

63. Randall, L.B.; Georgi, E.; Genzel, G.H.; Schweizer, H.P. Finafloxacin overcomes Burkholderia pseudomallei efflux-mediated fluoroquinolone resistance. J. Antimicrob Chemother. 2017, 72, 1258-1260. [CrossRef] [PubMed]

64. Barnes, K.B.; Hamblin, K.A.; Richards, M.I.; Laws, T.R.; Vente, A.; Atkins, H.S.; Harding, S.V. Demonstrating the protective efficacy of the novel fluoroquinolone finafloxacin against an inhalational exposure to burkholderia pseudomallei. Antimicrob. Agents Chemother. 2017, 61, e00082-17. [CrossRef]

65. Barnes, K.B.; Richards, M.I.; Laws, T.R.; Núñez, A.; Thwaite, J.E.; Bentley, C.; Harding, S.V. finafloxacin is an effective treatment for inhalational tularemia and plague in mouse models of infection. Antimicrob. Agents Chemother. 2021, 65, e02294-20. [CrossRef] [PubMed]

66. Park, H.S.; Kim, H.J.; Seol, M.J.; Choi, D.R.; Choi, E.C.; Kwak, J.H. In vitro and in vivo antibacterial activities of DW-224a, a new fluoronaphthyridone. Antimicrob. Agent Chemother. 2006, 50, 2261-2264. [CrossRef]

67. Kocsis, B.; Szabo, D. Zabofloxacin for chronic bronchitis. Drugs Today 2016, 52, 495-500. [CrossRef] 
68. Dong Wha Obtains Approval for Zabolante from MFDS (Press Release 20 March 2015). Available online: https: / www.dongwha.co.kr/english/customer/dnews/content.asp?t_idx=856 (accessed on 20 August 2021).

69. Dong Wha Pharm's Quinolone Antibacterial Agent, "Zabolante", Wins at the 19th KNDA (Press Release 28 February 2018). Available online: https://www.dong-wha.co.kr/english/customer/dnews/content.asp?t_idx=1139 (accessed on 20 August 2021).

70. Van Bambeke, F. Renaissance of antibiotics against difficult infections: Focus on oritavancin and new ketolides and quinolones. Ann. Med. 2014, 46, 512-529. [CrossRef]

71. Kwon, A.R.; Min, Y.H.; Ryu, J.M.; Choi, D.R.; Shim, M.J.; Choi, E.C. In vitro and in vivo activities of DW-224a, a novel fluoroquinolone antibiotic agent. J. Antimicrob. Chemother. 2006, 58, 684-688. [CrossRef] [PubMed]

72. Park, H.-S.; Oh, S.-H.; Kim, H.-S.; Choi, D.-R.; Kwak, J.-H. Antimicrobial activity of zabofloxacin against clinically isolated Streptococcus pneumoniae. Molecules 2016, 21, 1562. [CrossRef]

73. Jones, R.N.; Biedenbach, D.J.; Ambrose, P.G.; Wikler, M.A. Zabofloxacin (DW-224a) activity against Neisseria gonorrhoeae including quinolone-resistant strains. Diagn. Microbiol. Infect. Dis. 2008, 62, 110-112. [CrossRef]

74. Han, H.K.; Kim, S.E.; Shin, K.H.; Lim, C.; Lim, K.S.; Yu, K.S.; Cho, J.Y. Comparison of pharmacokinetics between new quinolone antibiotics: The zabofloxacin hydrochloride capsule and the zabofloxacin aspartate tablet. Curr. Med. Res. Opin. 2013, 29, 1349-1355. [CrossRef] [PubMed]

75. Rhee, C.K.; Chang, J.H.; Choi, E.G.; Kim, H.K.; Kwon, Y.S.; Kyung, S.Y.; Lee, J.-H.; Park, M.J.; Yoo, K.H.; Oh, Y.M. Zabofloxacin versus moxifloxacin in patients with COPD exacerbation: A multicenter, double-blind, double-dummy, randomized, controlled, phase III, non-inferiority trial. Int. J. Chron. Obstruct. Pulmon. Dis. 2015, 10, 2265-2275. [CrossRef] [PubMed] 